\title{
Microwave-assisted extraction of phenolic compounds from coffee (Coffea robusta L. Linden) bee pollen
}

\author{
LE PHAM TAN QUOC ${ }^{\circledR}$
}

Institute of Biotechnology and Food Technology

Industrial University of Ho Chi Minh City

Ho Chi Minh City, Vietnam

Address for correspondence: phone: +84 906413 493; e-mail: lephamtanquoc@iuh.edu.vn

\section{Summary}

Introduction: Coffee bee pollen contains some precious bioactive compounds, especially phenolic compounds. This material is easily found in many regions in Vietnam and is quite useful for human health.

Objective: The main aim of this study was to determine the best extraction conditions for the total polyphenol content (TPC) and antioxidant capacity (AC) of coffee (Coffea robusta L. Linden) bee pollen with microwave-assisted extraction (MAE).

Methods: TPC and AC of extract of coffee (C. robusta) bee pollen were determined using Folin-Ciocalteu (FC) and 2,2-diphenyl-1-picrylhydrazyl (DPPH) assay, respectively. In addition, micromorphology of sample was observed using scanning electron micrographs (SEM).

Results: The findings showed that all factors strongly affected the efficiency of the extraction process. The best extraction conditions obtained were ethanol concentration of $60 \%(v / v)$, solid to solvent ratio of $1 / 30$ $(w / v)$, extraction time of $7 \mathrm{~min}$, and a microwave power of $314 \mathrm{~W}$.

Conclusion: The highest TPC and AC obtained were $13.73 \mathrm{mg} \mathrm{GAE} / \mathrm{g}$ DW and $10.08 \mu \mathrm{mol}$ TE/g DW with aqueous ethanol as the solvent at the optimal extraction condition. In addition, the microstructures of the material changed insignificantly under microwave irradiation.

Key words: bee pollen, Coffea robusta, microwave, extraction, polyphenols

Słowa kluczowe: pytek pszczeli, Coffea robusta, mikrofale, ekstrakcja, polifenole

\section{INTRODUCTION}

A mixture called bee pollen consists of pollen, saliva, nectar, wax, and honey; it is collected from monofloral or polyfloral pollens by honey bees. The beehives use these bee pollens as their major food source. Farmers usually put the pollen traps in front of the entrance of the hive to collect the raw bee 
pollen in the honey bee farm $[1,2]$. Hence, the quality of bee pollen depends on the chemical composition of pollen. Recently, bee pollen has been used by food handlers as a source of healthy nutrients [3], with large amounts of many ingredients, such as carbohydrates, protein, lipid, fiber, and phenolic compounds [4]. In addition, this material has many benefits to human health, such as its antioxidant, antibacterial, anti-inflammatory, anticarcinogenic, and antiallergic properties [2].

Currently, the extraction of bioactive compounds from the plant has been popular with many different methods. For instance, Yen and Quoc [5] extracted the total steviosides content from Stevia rebaudiana Bertoni leaves using ultrasound-assisted extraction (UAE); Quoc and Muoi [6] used a microwave to isolate phenolic compounds from Polygonum multiflorum Thunb. roots, and Pinelo et al. [7] extracted phenolic compounds from grape pomace using the conventional method. Essentially, the use of microwave-assisted extraction (MAE) is a good solution due to the short extraction time, the high yield obtained, and its ease of use.

In Vietnam, the coffee plant (C. robusta) has been widely cultivated, especially in Gia Lai, Daklak, Daknong, Lam Dong province. The Vietnamese consume a large amount of coffee (nearly 162,000 tons in 2020) [8]. Therefore, the bee pollen from coffee is also potential food for humans in the future, thus, the nutritional exploitation of this material is quite necessary, especially for phenolic compounds. However, until now, no previous literature has mentioned this issue. For this reason, the purpose of this study was to research the effect of MAE conditions on the total polyphenol content (TPC) and antioxidant capacity (AC) of coffee bee pollen (CBP) from this plant and to obtain a better understanding of the chemical components and microstructure of this material.

\section{MATERIALS AND METHODS}

\section{Chemicals and sample preparation}

Folin-Ciocalteu (FC) and Trolox (6-hydroxy2,5,7,8-tetramethylchroman-2-carboxylic acid) reagent were purchased from Sigma-Aldrich (USA), while 2,2-diphenyl-1-picrylhydrazyl (DPPH) was purchased from Alfa Aesar (England). All other chemicals and solvents used in this study were of analytical reagent grade.

CBP pellets originated from Daklak province (Vietnam) and the sample was collected in February
(2021). The initial materials were solar-dried until the moisture was less than $10 \%$ and packed in a polyethylene (PE) bag. Next, they were stored at $29 \pm 1^{\circ} \mathrm{C}$. The CBP pellets were ground into a fine powder (less than $0.6 \mathrm{~mm}$ particle size) and then stored in a PE bag for further experiments.

\section{Extraction methodology}

Firstly, the MAE process was conducted by liquidsolid extraction using various solvents (water, 50\% $(v / v)$ aqueous ethanol, and $50 \%(v / v)$ aqueous acetone) in a microwave oven (Whirlpool, China). Then, in a specific experiment, the sample ( $2 \mathrm{~g})$ was extracted with the best solvent at concentrations of 40, 50, 60,70 , and $80 \%(v / v)$, with solid to solvent (SS) ratios of $1 / 15,1 / 20,1 / 25,1 / 30$, and $1: 35(w / v)$; extraction times of $1,3,5,7$, and $9 \mathrm{~min}$; and microwave powers of 244, 314, 383, and $453 \mathrm{~W}$. Then, the extract was filtered through Whatman filter paper (No. 4) and made up to $100 \mathrm{ml}$ with extraction solvent. The obtained extracts were analyzed for the total polyphenol content (TPC) and antioxidant capacity (AC).

\section{Determination of the TPC}

The TPC was determined by the FC assay according to the procedure of Quoc and Muoi [9]. $0.1 \mathrm{ml}$ of the obtained extracts reacted with $1.5 \mathrm{ml}$ of FC solution $(10 \%, v / v)$ and kept for $5 \mathrm{~min}$. Next, $4 \mathrm{ml}$ of sodium carbonate solution $(20 \%, w / v)$ was added, and then made up to $10 \mathrm{ml}$ with distilled water. The mixture was kept for $30 \mathrm{~min}$ in dark. The results are based on calibration curves obtained with gallic acid as a standard agent and the absorbance was determined at $738 \mathrm{~nm}$. The TPC is expressed as mg gallic acid equivalent per gram of dry weight (mg GAE/g DW).

\section{Determination of the AC}

The AC was measured by the DPPH assay according to the procedure of Quoc and Muoi [9]. In this study, $0.1 \mathrm{ml}$ of the obtained extract reacted with $4 \mathrm{ml}$ of $0.1 \mathrm{mM}$ DPPH solution in ethanol. The mixture was made up to $5 \mathrm{ml}$ with ethanol $(96 \%, v / v)$ and kept for $30 \mathrm{~min}$ in dark. Trolox was used as the standard and an absorbance at $517 \mathrm{~nm}$ was used to measure the AC. The obtained AC was expressed in Trolox equivalent antioxidant capacity and determined as $\mu \mathrm{mol}$ of Trolox per gram of dry weight ( $\mu \mathrm{mol}$ TE/g DW). 


\section{Scanning electron micrographs (SEM)}

A scanning electron microscope (SEM) (Jeol JSM6400, Japan) was used to evaluate the micromorphology of the samples and residues after the MAE process. SEM was determined at $5 \mathrm{kV}$ and at a vacuum pressure of $0.04 \mathrm{~Pa}$.

\section{Data analysis}

The experimental results were analyzed by the oneway analysis of variance (ANOVA) method and significant differences among the means from triplicate analyses at $p<0.05$ were determined by Fisher's least significant difference (LSD) procedure using Statgraphics software (Centurion XV). The values obtained were expressed in the form of a mean \pm standard deviation (SD). The experiment with the best results from the previous one was used for the next experiment.

Ethical approval: The conducted research is not related to either human or animal use.

\section{RESULTS AND DISCUSSION}

\section{Effects of the type of solvent on the total poly- phenol content (TPC) and antioxidant capacity (AC) in the coffee bee pollen (CBP) extract}

At first, the CBP sample was extracted with the following three solvents: distilled water, $50 \%(v / v)$ aqueous ethanol, and 50\% $(v / v)$ aqueous acetone. All experiments were carried out at a SS ratio of $1 / 20(w / v)$, an extraction time of $5 \mathrm{~min}$, and with a microwave power of $314 \mathrm{~W}$. The effects of the solvent on the TPC and $\mathrm{AC}$ in the extract are presented in table 1. The highest efficiency of MAE was reached when using $50 \%$ aqueous ethanol. The results showed that the highest TPC and AC values were $10.98 \mathrm{mg} \mathrm{GAE} / \mathrm{g}$ DW and $7.85 \mu \mathrm{mol} \mathrm{TE} / \mathrm{g}$ DW, respectively. According to Tan et al. [10], the increase in the polarity of the solvents was arranged in the following order: acetone
$>$ ethanol > water. Based on the obtained results, an increase in the polarity of the solvents can lead to an increase in the TPC and AC in this study. This proves that the MAE efficiency significantly depends on the polarity of the solvents and the solubility of different typical phenolic groups.

A previous study also pointed out that alcohol (ethanol) is the suitable solvent for the extraction of phenolic compounds in bee pollen, especially the phenolic acid group (vanillic acid, protocatechuic acid) and flavonoids group (rutin, quercetin) [11]. In addition, Galan et al. [12] indicated that ethanol is a strong microwave absorber; it can easily convert microwaves to heat, stimulate, and improve the extraction yield. Ethanol is also a safe, low-toxic solvent with a reasonable price, and it can be used widely in food technology.

The TPC in the CBP of this study was higher than the results reported by Kostić et al. [13], who extracted polyphenols from sunflower pollen (244.44 mg/kg DW) using 50\% aqueous ethanol by the conventional extraction method. This difference may be explained by the fact that there were different chemical components of the material and various extraction methods. According to the presented data, we can conclude that $50 \%$ aqueous ethanol is of great importance to achieving high yields.

\section{Effect of the ethanol concentration on the total polyphenol content (TPC) and antioxidant ca- pacity $(\mathrm{AC})$ in the coffee bee pollen (CBP)}

Experiments were carried out with the following factors: a SS ratio of $1 / 20(w / v)$, an extraction time of $5 \mathrm{~min}$, and a microwave power of $314 \mathrm{~W}$. The ethanol concentrations were adjusted from 40 to $80 \%$ $(v / v)$. The obtained results are shown in table 2 .

Basically, the TPC increased slightly as the aqueous ethanol concentration increased from 40 to $60 \%$ and steadily dropped for the rest of the concentrations. The tendency of AC was similar to that of TPC; however, the AC in the extract dropped dramatically for the 70 and $80 \%$ aqueous ethanol. Both TPC and AC in the extract peaked for the $60 \%$

Table 1.

Effect of the type of solvent on the extraction efficiency

\begin{tabular}{cccc}
\hline Solvent & Distilled water & Ethanol [50\%] & Acetone [50\%] \\
\hline TPC $[\mathrm{mg} \mathrm{GAE} / \mathrm{g} \mathrm{DW}]$ & $10.62 \pm 0.18^{\mathrm{b}}$ & $10.98 \pm 0.05^{\mathrm{c}}$ & $10.07 \pm 0.09^{\mathrm{a}}$ \\
\hline $\mathrm{AC}[\mu \mathrm{mol} \mathrm{TE} / \mathrm{g} \mathrm{DW}]$ & $5.52 \pm 0.12^{\mathrm{a}}$ & $7.85 \pm 0.09^{\mathrm{c}}$ & $6.12 \pm 0.13^{\mathrm{b}}$ \\
\hline
\end{tabular}

Different lowercase letters in the same row represent a statistically significant difference $(p<0.05)$ between various treatments. 
Table 2.

Effect of ethanol concentrations on the extraction efficiency

\begin{tabular}{lccccc}
\hline Ethanol concentrations $[\%, v / v]$ & 40 & 50 & 60 & 70 & 80 \\
\hline TPC $[\mathrm{mg} \mathrm{GAE} / \mathrm{g} \mathrm{DW}]$ & $10.70 \pm 0.09^{\mathrm{b}}$ & $10.96 \pm 0.08^{\mathrm{c}}$ & $11.37 \pm 0.08^{\mathrm{d}}$ & $10.72 \pm 0.17^{\mathrm{b}}$ & $9.38 \pm 0.01^{\mathrm{a}}$ \\
\hline AC $[\mu \mathrm{mol} \mathrm{TE} / \mathrm{g}$ DW $]$ & $5.10 \pm 0.07^{\mathrm{c}}$ & $7.48 \pm 0.14^{\mathrm{d}}$ & $8.29 \pm 0.09^{\mathrm{e}}$ & $4.01 \pm 0.13^{\mathrm{b}}$ & $0.04 \pm 0.04^{\mathrm{a}}$ \\
\hline
\end{tabular}

Different lowercase letters in the same row represent a statistically significant difference $(p<0.05)$ between various treatments.

aqueous ethanol (11.37 $\mathrm{mg} \mathrm{GAE} / \mathrm{g}$ DW for TPC and $8.29 \mu \mathrm{mol} \mathrm{TE} / \mathrm{g}$ DW for AC).

The TPC and AC values in this study are in agreement with the findings reported by Chirinos et al. [14]: solvents with very high or very low polarity do not exhibit good extraction efficiency. The combination of water with other organic solvents creates various polar mediums. A suitable polar medium can improve the extraction yield of polyphenols. This also proved that the phenolic compounds in CBP easily dissolve in a solvent that has a medium polarity. Ethanol concentrations from 50 to $60 \%(v / v)$ are commonly used in the extraction of polyphenols in plant materials. For instance, Galan et al. [12] and Rzepecka-Stojko et al. [15] extracted phenolic compounds from sea buckthorn leaves and bee pollen in Poland, respectively. From the results obtained, it appears that an ethanol concentration of $60 \%$ is the optimal condition for subsequent experiments.

\section{Effect of the solid to solvent (SS) ratio on the total polyphenol content (TPC) and antioxidant capacity (AC) in the coffee bee pollen (CBP)}

The fixed parameters in this experiment included an ethanol concentration of $60 \%$, an extraction time of $5 \mathrm{~min}$, and a microwave power of $314 \mathrm{~W}$. The SS ratios investigated were from $1 / 5$ to $1 / 35(w / v)$. The SS ratio is one of the most important factors that strongly affects the extraction efficiency of CBP. An optimal ratio may improve the TPC and AC in the extract and enhance economic efficiency.

Table 3 shows that the TPC and AC gradually increased with an increasing amount of solvent, up to $1 / 30(w / v)$, and slowly decreased at the ratio of $1 / 35(w / v)$. The best TPC and AC values were $13.69 \mathrm{mg} \mathrm{GAE} / \mathrm{g} \mathrm{DW}$ and $9.71 \mu \mathrm{mol} \mathrm{TE} / \mathrm{g} \mathrm{DW}$ at a ratio of $1 / 30(w / v)$. The optimal SS ratio of $1 / 30(w / v)$ obtained in this study is similar to that found in the study reported by Zhao et al. [16], where the authors extracted polyphenols from Melastoma sanguineum fruit. Besides, it is different from the study of $\mathrm{Al}-$ Farsi and Lee [17], who optimized the polyphenol extraction process from date seeds using a sample to solvent ratio of $1 / 60(w / v)$. These differences may be due to the different contents of the chemical components or the sizes of the extraction materials.

According to Al-Farsi and Lee [17], the high amount of solvent may promote an increase in a concentration gradient, leading to an increase in the diffusion rate of the soluble components in the initial material, resulting in greater extraction yield. On the contrary, a small amount of solvent cannot completely dissolve bioactive components because the chance of their exposure to solvent decreases. This also causes a lower extraction yield. Essentially, the extraction yields continue to rise once equilibrium is reached at a suitable ratio [18]. Through the above analysis, the SS ratio of $1 / 30(w / v)$ was chosen as the optimal extraction ratio.

\section{Effect of the extraction time on the total poly- phenol content (TPC) and antioxidant capacity (AC) in the coffee bee pollen (CBP)}

In order to investigate the influence of different extraction times on the TPC and AC in the extract, several extraction times $(1,3,5,7$, and $9 \mathrm{~min})$ were

Table 3.

Effect of solid to solvent (SS) ratios on the extraction efficiency

\begin{tabular}{lccccc}
\hline \multicolumn{1}{c}{ SS ratios $[w / v]$} & $1 / 15$ & $1 / 20$ & $1 / 25$ & $1 / 30$ & $1 / 35$ \\
\hline TPC $[\mathrm{mg} \mathrm{GAE} / \mathrm{g} \mathrm{DW}]$ & $10.78 \pm 0.09^{\mathrm{a}}$ & $11.33 \pm 0.09^{\mathrm{b}}$ & $11.90 \pm 0.11^{\mathrm{c}}$ & $13.69 \pm 0.19^{\mathrm{e}}$ & $13.34 \pm 0.16^{\mathrm{d}}$ \\
\hline $\mathrm{AC}[\mu \mathrm{mol} \mathrm{TE} / \mathrm{g} \mathrm{DW}]$ & $5.25 \pm 0.13^{\mathrm{a}}$ & $8.22 \pm 0.13^{\mathrm{b}}$ & $8.29 \pm 0.14^{\mathrm{b}}$ & $9.71 \pm 0.14^{\mathrm{d}}$ & $9.30 \pm 0.12^{\mathrm{c}}$ \\
\hline
\end{tabular}

Different lowercase letters in the same row represent a statistically significant difference $(p<0.05)$ between various treatments. 
investigated, keeping the other three factors constant (an ethanol concentration of $60 \%$, a SS ratio of $1 / 30(w / v)$, and a microwave power of $314 \mathrm{~W})$.

Extraction time is the main factor that influences the efficiency of polyphenol extraction. As seen in table 4, the yield of polyphenols increased from 12.36 to $13.79 \mathrm{mg} \mathrm{GAE} / \mathrm{g} \mathrm{DE}$ for TPC and from 7.19 to $10.21 \mu \mathrm{mol} \mathrm{TE} / \mathrm{g} \mathrm{DW}$ for AC in the extract when the extraction time increased from 1 to $7 \mathrm{~min}$, respectively. Then, both the TPC and AC decreased slightly for longer extraction time.

The increase in extraction time leads to higher extraction efficiency because the solvent can easily penetrate the cell membrane and enhance the transfer rate from the cell to the solvent. The bioactive compounds in the raw materials diffuse easily from the plant cell to the solvent. However, at longer times, these compounds could be hydrolyzed and oxidized because they are exposed to light and oxygen in an ambient environment; therefore, the extraction yield will be reduced [19].

Basically, the extraction time in the MAE process is quite low (usually less than $10 \mathrm{~min}$ ). This result is consistent with the reports of Hayat et al. [20] and Wu et al. [21], who extracted polyphenols from citrus mandarin peels (49 s) and potato downstream wastes (2 min) using MAE, respectively. In addition, the extraction time in MAE is lower than that used in other methods. For instance, Quoc and Muoi [22] extracted polyphenols from Polygonum multiflorum Thunb. root using pectinase-assisted extraction for $80 \mathrm{~min}$ and Aybastier et al. [23] extracted polyphenols from blackberry leaves using UAE for 105 and $117 \mathrm{~min}$.

Consequently, the extraction time of $7 \mathrm{~min}$ was considered suitable to gain maximum TPC and AC for the polyphenol extraction from CBP.

\section{Effect of the microwave power on the total po- lyphenol content (TPC) and antioxidant capa- city (AC) in the coffee bee pollen (CBP)}

From the results obtained above, the fixed factors in this experiment included an ethanol concentration of $60 \%$, a SS ratio of $1 / 30(w / v)$, and an extraction time of $7 \mathrm{~min}$. The microwave power was 244, 314, 383 , and $453 \mathrm{~W}$. The extraction efficiency is shown in table 5 .

Table 5 shows the variation in TPC and AC according to the different microwave powers. The tendency of TPC increased from $11.93 \mathrm{mg}$ GAE/g DW at $244 \mathrm{~W}$ to $14.10 \mathrm{mg} \mathrm{GAE} / \mathrm{g} \mathrm{DW}$ at $383 \mathrm{~W}$ and then decreased at higher microwave powers. However, the change in TPC values between 314 and $383 \mathrm{~W}$ is not significantly different $(p>0.05)$, while the AC values steadily dropped from $10.18 \mathrm{mg} \mu \mathrm{mol} \mathrm{TE} / \mathrm{g} \mathrm{DW}$ at $244 \mathrm{~W}$ to $8.93 \mu \mathrm{mol} \mathrm{TE} / \mathrm{g}$ DW at $453 \mathrm{~W}$. The AC values at 244 and $314 \mathrm{~W}$ vary insignificantly. Therefore, the microwave power of $314 \mathrm{~W}$ is the best choice for this experiment. Compared to other previous studies, the optimal microwave power in this study is lower than that in the study reported by Kaderides et al. [24], where the authors extracted polyphenols from pomegranate peels at $600 \mathrm{~W}$. The microwave power in our study is also higher than that found in a report recorded by Hayat et al. [20], who optimized MAE of phenolic acids from citrus mandarin peels at $152 \mathrm{~W}$. This can be explained by the fact that the extraction yield may depend on the structure of the materials.

An increase in microwave powers can lead to an rapid increase in the temperature. In addition, at high temperatures, the solvent's surface tension and viscosity will decrease. The solubility and diffusion coefficient of the components in the materials also increase.

Table 4.

Effect of extraction time on the extraction efficiency

\begin{tabular}{rccccc}
\hline Time $[\mathrm{min}]$ & 1 & 3 & 5 & 7 & 9 \\
\hline TPC $[\mathrm{mg}$ GAE/g DW $]$ & $12.36 \pm 0.11^{\mathrm{a}}$ & $12.50 \pm 0.13^{\mathrm{a}}$ & $13.55 \pm 0.09^{\mathrm{b}}$ & $13.79 \pm 0.13^{\mathrm{c}}$ & $13.42 \pm 0.09^{\mathrm{b}}$ \\
\hline AC $[\mu \mathrm{mol} \mathrm{TE} / \mathrm{g} \mathrm{DW}]$ & $7.19 \pm 0.12^{\mathrm{a}}$ & $7.73 \pm 0.14^{\mathrm{b}}$ & $9.75 \pm 0.07^{\mathrm{d}}$ & $10.21 \pm 0.12^{\mathrm{e}}$ & $8.80 \pm 0.12^{\mathrm{c}}$ \\
\hline
\end{tabular}

Different lowercase letters in the same row represent a statistically significant difference $(p<0.05)$ between various treatments.

Table 5.

Effect of microwave power on the extraction efficiency

\begin{tabular}{lcccc}
\hline \multicolumn{1}{c}{ Microwave power $[\mathrm{W}]$} & 244 & 314 & 383 & 453 \\
\hline TPC $[\mathrm{mg}$ GAE/g DW $]$ & $11.93 \pm 0.03^{\mathrm{b}}$ & $13.73 \pm 0.37^{\mathrm{c}}$ & $14.10 \pm 0.29^{\mathrm{c}}$ & $11.74 \pm 0.11^{\mathrm{a}}$ \\
\hline AC $[\mu \mathrm{mol} \mathrm{TE} / \mathrm{g}$ DW $]$ & $10.18 \pm 0.07^{\mathrm{c}}$ & $10.08 \pm 0.14^{\mathrm{c}}$ & $9.55 \pm 0.12^{\mathrm{b}}$ & $8.93 \pm 0.12^{\mathrm{a}}$ \\
\hline
\end{tabular}

Different lowercase letters in the same row represent a statistically significant difference $(p<0.05)$ between various treatments. 
The solvent easily penetrates into the material layer, resulting in an increase in the exposure between the material and the solvent. Therefore, the extraction efficiency significantly improves. However, polyphenols are thermally sensitive compounds. Hence, they easily degrade at high microwave powers [24, 25].

\section{Scanning electron micrographs (SEM) of the coffee bee pollen (CBP) before and after extrac- tion process}

Figure $1 \mathrm{~A}, \mathrm{~B}$ shows that the $\mathrm{CBP}$ pellets were ground into many CBP grains (20-30 $\mu \mathrm{m}$ particle size). They stick together due to nectar and honey and form some bigger blocks. On the surface of the grains, there are some slight clefts. Under the irradiation of the microwave, the particle size of CBP grains is almost unchanged. However, CBP grains seem to appear with more wide clefts, wrinkles, and are incoherent (fig. $1 \mathrm{X}, \mathrm{Y})$. The change in the structure of CBP is not significant due to the particle size is quite small.

According to Kaderides et al. [24], microwaves create an increase in the internal pressure inside the sample, stimulating cell rupture and destroying the sample surface. Consequently, the bioactive compounds were easily released into the solvent. Compared to other studies, the significant change in the structure of the extraction material after microwave treatment was found in previous observations for tobacco leaves and pumpkin seeds, reported by Zhou et al. [26] and Jiao et al. [27], respectively.

\section{CONCLUSION}

In general, the results presented in this study show that the TPC and AC extracted from the CBP were significantly affected by the type of solvent, SS ratio, solvent concentration, irradiation time, and $\mathrm{mi}-$ crowave power. The best extraction conditions for the phenolic compounds of CBP were an ethanol concentration of $60 \%(v / v)$, SS ratio of $1 / 30(w / v)$, extraction time of $7 \mathrm{~min}$, and microwave power of $314 \mathrm{~W}$. In addition, the microstructure of CBP changed insignificantly under microwave treatment. Basically, the CBP are a potential phytochemical source for the functional food market.

\section{ACKNOWLEDGMENTS}

This research was performed at the Institute of Biotechnology and Food Technology, Industrial University of Ho Chi Minh City (Vietnam). The author would like to sincerely thank Nguyen Thi My
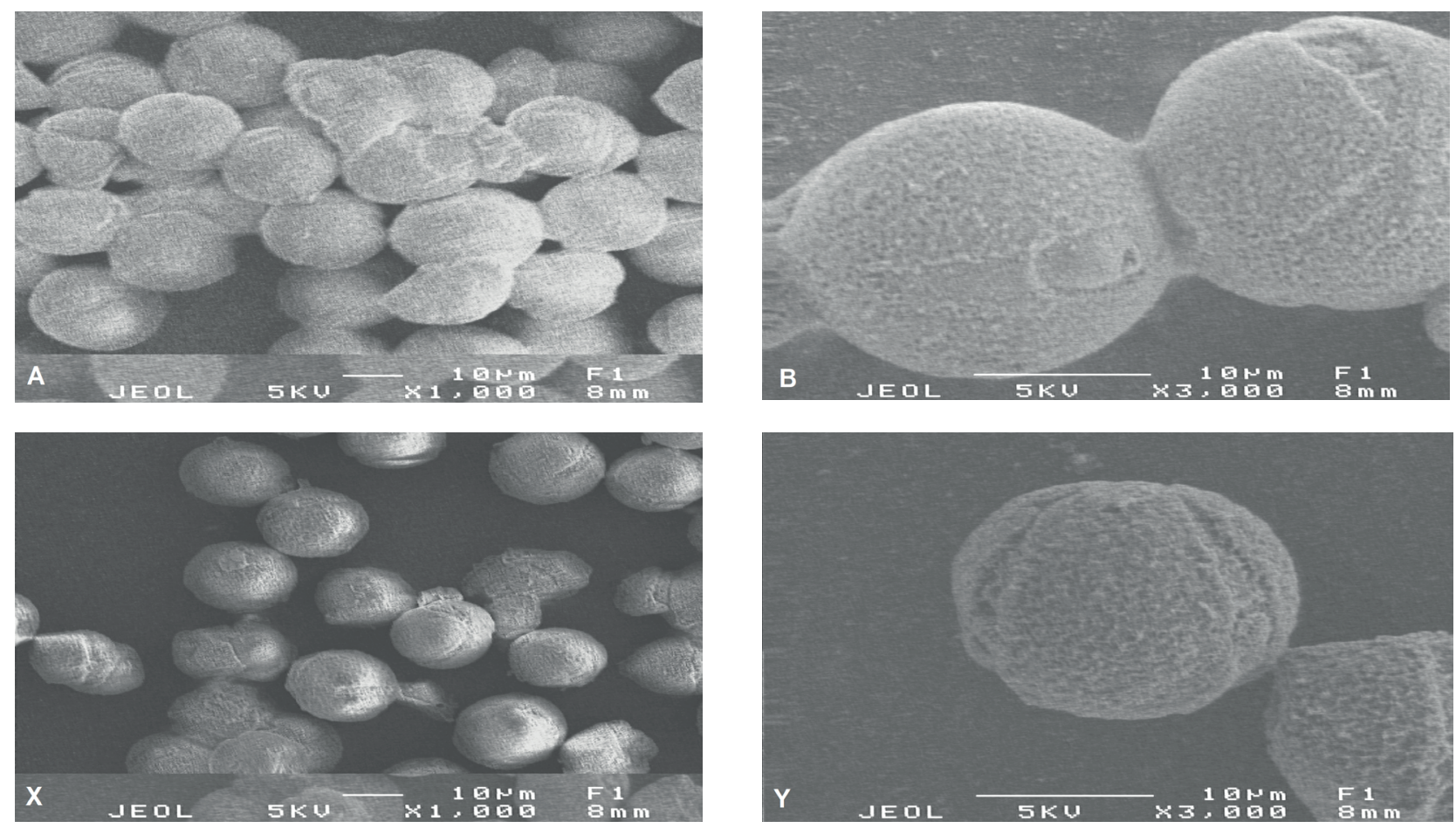

Figure 1.

SEM of CBP grains before $(\mathrm{A}, \mathrm{B})$ and $\operatorname{after}(\mathrm{X}, \mathrm{Y})$ the extraction process at various magnifications 
Diem and Huynh Ai Quy for their helpful advice on various technical issues examined in this paper.

Conflict of interest: Authors declare no conflict of interest.

\section{REFERENCES}

1. Almeida-Muradian LB, Pamplona LC, Coimbra S, Barth OM. Chemical composition and botanical evaluation of dried bee pollen pellets. J Food Compos Anal 2005; 18:105-11. doi: http://dx.doi. org/10.1016/j.jfca.2003.10.008

2. Li QQ, Wang K, Marcucci MC, Sawaya ACHF, $\mathrm{Hu}$ L, Xue AF et al. Nutrient-rich bee pollen: A treasure trove of active natural metabolites. J Funct Foods 2018; 49:472-484. doi: http://dx.doi. org/10.1016/j.jff.2018.09.008

3. Sattler JAG, de Melo ILP, Granato D, Araújo E, de Freitas ADS, Barth OM et al. Impact of origin on bioactive compounds and nutritional composition of bee pollen from southern Brazil. Food Res Int 2015; 77:82-91. doi: http://dx.doi. org/10.1016/j.foodres.2015.09.013

4. Komosinska-Vassev K, Olczyk P, Kafmierczak J, Mencner L, Olczyk K. Bee pollen: Chemical composition and therapeutic application. J Evidence-Based Complementary Altern Med 2015; ID 297425.

5. Yen NTH, Quoc LPT. Chemical composition of dried Stevia rebaudiana Bertoni leaves and effect of ultrasound-assisted extraction on total steviosides content in extract. Herba Pol 2021; 67(1):17. doi: http://dx.doi.org/10.2478/hepo-2021-0003

6. Quoc LPT, Muoi NV. Microwave-assisted extraction of phenolic compounds from Polygonum multiflorum Thunb. roots. Acta Sci Pol Technol Aliment 2016; 15(2):181-189. doi: http://dx.doi. org/10.17306/J.AFS.2016.2.18

7. Pinelo M, Rubilar M, Jerez M, Sineiro J, Núnez MJ. Effect of solvent, temperature, and solvent-tosolid ratio on the total phenolic content and antiradical activity of extracts from different components of grape pomace. J Agric Food Chem 2005; 53:2111-2117.

8. Statista Research Department. http://www.statista.com/statistics/315003/vietnam-total-coffeeconsumption, accessed in March 18. 2021.
9. Quoc LPT, Muoi NV. Effects of treatment methods on total polyphenol content and antioxidant activity of Polygonum multiflorum Thunb. root extract. Annals Food Sci Technol 2015; $16(1): 78-84$.

10. Tan MC, Tan CP, Ho CW. Effects of extraction solvent system, time and temperature on total phenolic content of henna (Lawsonia inermis) stems. Int Food Res J 2013; 20(6):3117-3123.

11. Ares AM, Valverde S, Bernal JL, Nozal MJ, Bernal J. Extraction and determination of bioactive compounds from bee pollen. J Pharm Biomed Anal 2018; 147:110-124. doi: http://dx.doi. org/10.1016/j.jpba.2017.08.009

12. Galan AM, Calinescu I, Trifan A, WinkworthSmith C, Calvo-Carrascal M, Dodds C et al. New insights into the role of selective and volumetric heating during microwave extraction: Investigation of the extraction of polyphenolic compounds from sea buckthorn leaves using microwaveassisted extraction and conventional solvent extraction. Chem Eng Process 2017; 116:29-39. doi: http://dx.doi.org/10.1016/j.cep.2017.03.006

13. Kostić AŽ, Milinčić DD, Gašić UM, Nedić N, Stanojević SP, Tešić ŽL et al. Polyphenolic profile and antioxidant properties of bee-collected pollen from sunflower (Helianthus annuus L.) plant. LWT - Food Sci Technol 2019; 112:108244. doi: http://dx.doi.org/10.1016/j.lwt.2019.06.011

14. Chirinos R, Rogez H, Campos D, Pedreschi R, Larondelle Y. Optimization of extraction conditions of antioxidant phenolic compounds from mashua (Tropaeolum tuberosum Ruíz \& Pavón) tubers. Sep Purif Technol 2007; 55:217-225. doi: http://dx.doi.org/10.1016/j.seppur.2006.12.005

15. Rzepecka-Stojko A, Stojko J, Kurek-Górecka A, Górecki M, Sobczak A, Stojko R et al. Polyphenol content and antioxidant activity of bee pollen extracts from Poland. J Apic Res 2016; 54(5):482490. doi: http://dx.doi.org/10.1080/00218839.201 6.1186916

16. Zhao CN, Zhang JJ, Li Y, Meng X, Li HB. Microwave-assisted extraction of phenolic compounds from Melastoma sanguineum fruit: Optimization and identification. Molecules 2018; 23(10):ID 2498. doi: http://dx.doi.org/10.3390/ molecules 23102498 
17. Al-Farsi MA, Lee CY. Optimization of phenolics and dietary fibre extraction from date seeds. Food Chem 2008; 108:977-985. doi: http://dx.doi. org/10.1016/j.foodchem.2007.12.009

18. Herodež ŠS, Hadolin M, Škerget M, Knez Ž. Solvent extraction study of antioxidants from Balm (Melissa officinalis L.) leaves. Food Chem 2003; 80:275-282. doi: http://dx.doi.org/10.1016/ S0308-8146(02)00382-5

19. Naczk M, Shahidi F. Extraction and analysis of phenolics in food. J Chromatogr A 2004; 1054:97-103. doi: http://dx.doi.org/10.1016/j. chroma.2004.08.059

20. Hayat K, Hussain S, Abbas S, Farooq U, Ding B, $\mathrm{Xia} S$ et al. Optimized microwave-assisted extraction of phenolic acids from citrus mandarin peels and evaluation of antioxidant activity in vitro. Sep Purif Technol 2009; 70:63-70. doi: http://dx.doi. org/10.1016/j.seppur.2009.08.012

21. Wu T, Yan J, Liu R, Marcone MF, Aisa HA, Tsao R. Optimization of microwave-assisted extraction of phenolics from potato and its downstream waste using orthogonal array design. Food Chem 2012; 133:1292-1298. doi: http://dx.doi.org/10.1016/j. foodchem.2011.08.002

22. Quoc LPT, Muoi NV. Pectinase-assisted extraction of phenolic compounds from Polygonum multiflorum Thunb. root. Carpathian J Food Sci Technol 2017; 9(3):30-37.
23. Aybastier O, Isık E, Sahin S, Demir C. Optimization of ultrasonic-assisted extraction of antioxidant compounds from blackberry leaves using response surface methodology. Ind Crops Prod 2013;44:558-565. doi: http://dx.doi.org/10.1016/j. indcrop.2012.09.022

24. Kaderides K, Papaoikonomou L, Serafim M, Goula AM. Microwave-assisted extraction of phenolics from pomegranate peels: Optimization, kinetics, and comparison with ultrasounds extraction. Chem Eng Process 2019; 137:1-11. doi: http://dx.doi.org/10.1016/j.cep.2019.01.006

25. Spigno G, De Faveri DM. Antioxidants from grape stalks and marc: Influence of extraction procedure on yield, purity and antioxidant power of the extracts. J Food Eng 2007; 78:793-801. doi: http://dx.doi.org/10.1016/j.jfoodeng.2005.11.020

26. Zhou HY, Liu CZ. Microwave-assisted extraction of solanesol from tobacco leaves. J Chromatogr A 2006; 1129:135-139. doi: http://dx.doi. org/10.1016/j.chroma.2006.07.083

27. Jiao J, Li ZG, Gai QY, Li XJ, Wei FY, Fu YJ et al. Microwave-assisted aqueous enzymatic extraction of oil from pumpkin seeds and evaluation of its physicochemical properties, fatty acid compositions and antioxidant activities. Food Chem 2014; 147:17-24. doi: http://dx.doi.org/10.1016/j. foodchem.2013.09.079 